\section{The prevalence and determi- nants of body dysmorphic disorder among young social media users: A cross-sectional study}

\author{
Mohammed Saud Alsaidan, ${ }^{1}$ \\ Nawaf Saad Altayar, ${ }^{2}$ Saqer Habeeb \\ Alshmmari, ${ }^{2}$ Meshari Mahud \\ Alshammari, ${ }^{2}$ Faisal Turki Alqahtani, ${ }^{2}$ \\ Khaled Abdullah Mohajer, ${ }^{3,4}$ \\ ${ }^{1}$ Internal Medicine Department, College \\ of Medicine, Prince Sattam bin \\ Abdulaziz University; ${ }^{2}$ Internal \\ Medicine Department, Prince Sattam \\ bin Abdulaziz University, Al-Kharj; \\ ${ }^{3}$ Department of Dermatology, King Saud \\ Medical City, Riyadh; ${ }^{4}$ College of \\ Medicine, Dar Al Uloom University, \\ Riyadh, Saudi Arabia
}

\begin{abstract}
Social media that is heavily used in Saudi Arabia has been linked to a negative impact on body image satisfaction. The objective of the current study was to examine the burden, determinants, and impacts of Body Dysmorphic Disorder (BDD) among a community sample of social media users in Saudi Arabia. The Internet-based cross-sectional study was conducted among social media users during January and February 2020. BDD was assessed using a validated BDD Questionnaire. A total of 1010 participants were included in the current analysis. A total of $42(4.2 \%)$ met the criteria of BDD, with higher prevalence in younger participants. The defects of high concerns were skin disfigurements $(64.2 \%)$ and hair issues $(42.3 \%)$. BDD was significantly associated with spending a longer time on Snapchat and Instagram and less interest in religious topics. BDD group was more likely to compare their appearance with famous people in social media. BDD group reported more harassment and more history of psychiatric problems. There is a need to educate the public about the risk of BDD and to promote safe social networking.
\end{abstract}

\section{Introduction}

While most of the people may feel some degree of dissatisfaction with their appearance at times, ${ }^{1}$ individuals with Body Dysmorphic Disorder (BDD) experience persistent and intrusive thoughts about illu- sory flaws or defects in their appearance. ${ }^{2}$ BDD is categorized under obsessive-compulsive and related disorders, and the etiology is probably multifactorial, including cognitive deficits, psychological impairment, and neurochemical abnormalities. ${ }^{3,4}$ BDD is a relatively common but often underdiagnosed disorder. The prevalence in the general population has been estimated internationally between $1.9 \%$ and $3.3 \%$.

BDD is usually manifested as excessive mirror checking or mirror avoidance, camouflaging certain body parts, seeking reassurance, and excessive evaluation. ${ }^{2}$ Patients with BDD are frequently seen seeking correction at plastic surgery and dermatology clinics. ${ }^{6}$ Additionally, they are more frequently seen at psychiatric clinics with mood and anxiety disorders. ${ }^{7}$ The prevalence is several folds higher among cosmetic, dermatology, and psychiatric patients compared to the general population. ${ }^{5}$ Patients with BDD have a poor quality of life and impaired psychosocial functioning, irrespective of the presence of psychological comorbidity. 8,9

Saudi Arabia is considered a leading country in the Middle East in using social media. ${ }^{10}$ Social media could have a negative impact on body image satisfaction. ${ }^{11-13}$ The prevalence of BDD in Saudi Arabia has been examined only in female students, ${ }^{14,15}$ and dermatology patients. ${ }^{16,17}$ There is a lack of data estimating the prevalence of BDD in the general population. Additionally, BDD determinants and impacts received little attention. ${ }^{16}$ Moreover, the association of social media use and interest with BDD has never been examined. The objective of the current study was to examine the burden, determinants, and impacts of BDD among a community sample of social media users in Saudi Arabia. Additionally, to examine the association between BDD and the use of different social media applications.

\section{Materials and Methods}

\section{Population}

The current study was a communitybased study among medical students, university employees, families, and friends. The students and employees were enrolled in Prince Sattam bin Abdulaziz University at Al-Kharj city, Saudi Arabia. The population was residents of Al-Kharj and Riyadh cities who agreed to join an internet-based study.

\section{Design}

It was a cross-sectional internet-based
Correspondence: Mohammed Saud Alsaidan, Internal Medicine Department, College of Medicine, Prince Sattam bin Abdulaziz University, Al-Kharj, Saudi Arabia.

Tel.: +966115886144, +966551113300

E-mail: dr.saidan@hotmail.com

Key words: Body dysmorphic disorder; body image; social media; psychiatry; dermatology.

Acknowledgements: The authors acknowledge the Deanship of Scientific Research at Prince Sattam bin Abdulaziz University, Alkharj, Saudi Arabia for supporting the publication.

Conflict of interests: The authors declare no potential conflict of interests.

Ethics approval and consent to participate: The study design obtained the required ethical approvals of the ethical committee of the Prince Sattam bin Abdulaziz University. The consent to participate was a part of the questionnaire.

Received for publication: 3 July 2020. Accepted for publication: 28 October 2020.

This work is licensed under a Creative Commons Attribution-NonCommercial 4.0 International License (CC BY-NC 4.0).

CCopyright: the Author(s), 2020

Licensee PAGEPress, Italy

Dermatology Reports 2020; 12:8774

doi:10.4081/dr.2020.8774

study conducted during January and February 2020. The study design obtained the required ethical approvals of the ethical committee of the Prince Sattam bin Abdulaziz University.

\section{Sample size and sampling}

Previous studies done internationally showed that the prevalence of BDD in the general population is around $2 \%-3 \%,{ }^{5}$ while the studies done in Saudi Arabia showed that the prevalence of BDD in students is around $4 \%-12 \% .^{14,15}$ It was estimated that a total of 811 patients would be required to detect a prevalence of BDD of 5\% with a confidence limit of $1.5 \%$, using a $95 \%$ confidence level and $80 \%$ power. The participants were recruited by medical students who sent text messages to friends, families, and relatives, inviting them to join the study and sending an electronic link to fill the questionnaire. A total of 1034 participants responded to the study questionnaire. Out of them, 24 participants were excluded due to non-Saudi nationality $(\mathrm{N}=16)$, age $<15$ years $(\mathrm{N}=7)$, and not using the internet $(\mathrm{N}=1)$. 


\section{Data collection tool}

Internet-based study questionnaire was created in Arabic language. It included questions about the socio-demographic characteristics of the participants as well as their social media use and interest, and possible BDD-related concerns, harassment, and psychiatric problems. The study questionnaire was validated by two experts and by doing a pilot study on 22 persons. BDD was assessed using the Body Dysmorphic Disorder Questionnaire (BDDQ), which is a brief, self-reported measure derived from the Diagnostic and Statistical Manual of Mental Disorders, 4th Edition (DSM-IV) diagnostic criteria for BDD. ${ }^{18}$ The questionnaire was developed as a screening instrument for BDD in psychiatric settings and has been validated in different patient and community settings. ${ }^{19,20}$ The BDDQ is formed of 5 close-ended questions which ask the respondents whether their appearance concerns are sources of preoccupation and, if so, it assesses the degree to which they cause distress or interfere with the person's social or occupational functioning. The BDD diagnosis is met when the individual answer yes to the first two questions, any of the four items of the third question, and to $b$ or $c$ items of the fourth question, and no to the last question (Table 1). The study questionnaire and the BDDQ were translated from English to Arabic by a bilingual colleague and then back to English by another bilingual colleague. The original and back-translated questionnaires showed no difference.

\section{Statistical analysis}

Categorical variables were presented as frequencies and percentages. Continuous variables were presented as means and Standard Deviations (SD). The differences in socio-demographic characteristics, social media use and interest, and possible BDDrelated concerns, harassment, and psychiatric problems were compared between participants who had BDD and those who did not. Chi-squared test or Fisher's exact test, as appropriate, were used to evaluate categorical differences, and t-test or Mann Whitney test, as appropriate, were used to evaluate continuous differences. All p-values were two-tailed. A p-value $<0.05$ was considered significant. Statistical Package for the Social Sciences software (SPSS Version 25.0. Armonk, NY: IBM Corp) was used for all statistical analyses.

\section{Results}

A total of 1010 participants were included in the current analysis. Table 1 shows the criteria used for diagnosing BDD and its prevalence among the included participants. Approximately 614 (60.8\%) participants were very concerned about the appearance of some part(s) of their bodies that they considered especially unattractive. Of them, $396(64.5 \%)$ participants were

Table 1. Prevalence and criteria of Body Dysmorphic Disorder (BDD) among included participants (N=1010).

\begin{tabular}{|c|c|c|}
\hline Criteria & $\begin{array}{c}\text { Number } \\
(\%)\end{array}$ & $\begin{array}{c}\text { Meeting } \\
\text { BDD definition }\end{array}$ \\
\hline $\begin{array}{l}\text { 1. Are you very concerned about the appearance of some part(s) of your body that you consider especially unattractive? } \\
\text { No } \\
\text { Yes }\end{array}$ & $\begin{array}{l}396(39.2) \\
614(60.8)\end{array}$ & $396(39.2)$ \\
\hline $\begin{array}{l}\text { 2. Do these concerns preoccupy you? That is, do you think about them a lot and wish you could think about them less? } \\
\text { No } \\
\text { Yes }\end{array}$ & $\begin{array}{l}218(35.5) \\
396(64.5)\end{array}$ & \\
\hline $\begin{array}{l}\text { Responded positively to the above two questions } \\
\text { No } \\
\text { Yes }\end{array}$ & $\begin{array}{l}614(60.8) \\
396(39.2)\end{array}$ & \\
\hline $\begin{array}{l}\text { 3a. Has your defect(s) caused you a lot of distress, torment, or pain? } \\
\text { No } \\
\text { Yes }\end{array}$ & $\begin{array}{l}157(39.6) \\
239(60.4)\end{array}$ & 321 (81.1) \\
\hline $\begin{array}{l}\text { 3b. Has your defect(s) significantly interfered with your social life? } \\
\text { No } \\
\text { Yes }\end{array}$ & $\begin{array}{l}217(54.8) \\
179(45.2)\end{array}$ & \\
\hline $\begin{array}{l}\text { 3c. Has your defect(s) significantly interfered with your schoolwork, your job, or your ability to function in your role? } \\
\text { No } \\
\text { Yes }\end{array}$ & $\begin{array}{l}272(68.7) \\
124(31.3)\end{array}$ & \\
\hline $\begin{array}{l}\text { 3d. Are there things you avoid because of your defect(s)? } \\
\text { No } \\
\text { Yes }\end{array}$ & $\begin{array}{l}156(39.4) \\
240(60.6)\end{array}$ & \\
\hline $\begin{array}{l}\text { Having one of the above four impacts } \\
\text { No } \\
\text { Yes } \\
\text { Total }\end{array}$ & $\begin{array}{c}75(19.9) \\
321(81.1) \\
396(100.0)\end{array}$ & \\
\hline $\begin{array}{l}\text { 4. How much time do you spend thinking about your defect(s) per day on average? } \\
\begin{array}{ll}\text { a. } & \text { Less than } 1 \text { hour a day } \\
\text { b. } & 1-3 \text { hours a day } \\
\text { c. } & \text { More than } 3 \text { hours a day } \\
\text { Total } & \end{array}\end{array}$ & $\begin{array}{l}187(58.3) \\
91(28.3) \\
43(13.4) \\
321(100.0)\end{array}$ & 134 (41.7) \\
\hline $\begin{array}{l}\text { 5. Is your main concern with your appearance that you aren't thin enough or that you might become fat? } \\
\text { No } \\
\text { Yes } \\
\text { Total }\end{array}$ & $\begin{array}{c}42(31.3) \\
92(68.7) \\
134(100.0)\end{array}$ & 42 (31.3) \\
\hline
\end{tabular}


preoccupied with these concerns to the extent they thought about them a lot and wished they could think about them less. Of the 396 participants who responded positively to the previous two questions, 321 $(81.1 \%)$ had one or more of the four examined impacts of the above-mentioned defects. These include 239 (60.4\%) participants who had a lot of distress, torment, or pain; 179 (45.2\%) who had significant interference with social life, 124 (31.3\%) who had significant interference with school work, job, or ability to function in their role, $240(60.6 \%)$ who had to avoid things because of their defect(s). Of the 321 participants who had one or more of the four above mentioned impacts, 134 (41.7\%) spent on average one hour or more per day thinking about their $\operatorname{defect}(\mathrm{s})$. However, 92 $(68.7 \%)$ of those thinking about their defect(s) had the main concern with their appearance as being not thin enough or becoming fat, indicating an eating disorder rather than BDD. Therefore, the prevalence of BDD was $4.2 \%$ (42/1010) when considering all participants (Figure 1).

Table 2 shows the socio-demographic characteristics of the participants by BDD status. The average age was $22.9 \pm 7.1$ years, and $54.0 \%$ of the participants were females. The majority of the participants were single $(84.3 \%)$ and students (68.2\%). The most common educational level was high school or less $(45.1 \%)$, followed by a bachelor degree $(41.9 \%)$ and finally diploma/postgraduate $(13.0 \%)$. The average family income was very variable, with $24.8 \%$ of the participants got less than 5,000 Saudi Riyals per month, and $10.0 \%$ got at least 30,000 Saudi Riyals per month. Age was

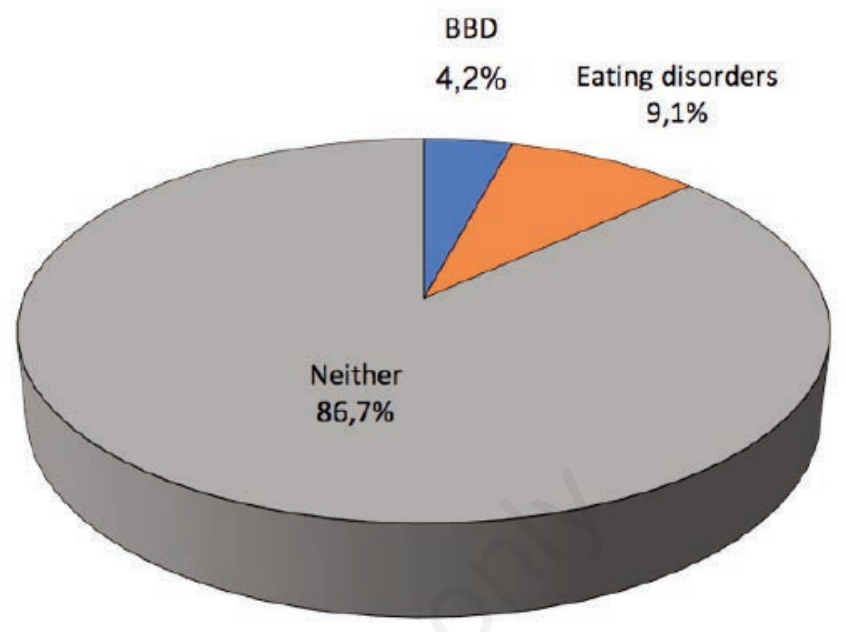

Figure 1. Prevalence of Body Dysmorphic Disorder (BDD) and eating disorders among included participants $(\mathrm{N}=1010)$.

Table 2. Socio-demographic characteristics by Body Dysmorphic Disorder (BDD) status among included participants ( $N=1010)$.

\begin{tabular}{|c|c|c|c|c|}
\hline & $\mathrm{BDD}, \mathrm{N}=42(\%)$ & No BDD, $N=968(\%)$ & Total, N=1010 (\%) & p-value \\
\hline $\begin{array}{l}\text { Age (years) } \\
\text { Mean } \pm \text { SD* } \\
<20 \\
20-25 \\
>25\end{array}$ & $\begin{array}{l}20.2 \pm 3.0 \\
22(52.4) \\
18(42.9) \\
2(4.8)\end{array}$ & $\begin{array}{l}23.0 \pm 7.2 \\
310(32.1) \\
501(51.8) \\
156(16.1)\end{array}$ & $\begin{array}{l}22.9 \pm 7.1 \\
332(32.9) \\
519(51.4) \\
158(15.7)\end{array}$ & $\begin{array}{l}0.014^{*} \\
0.011\end{array}$ \\
\hline $\begin{array}{l}\text { Gender } \\
\text { Male } \\
\text { Female } \\
\end{array}$ & $\begin{array}{l}17(40.5) \\
25(59.5)\end{array}$ & $\begin{array}{l}448(46.3) \\
520(53.7)\end{array}$ & $\begin{array}{l}465(46.0) \\
545(54.0)\end{array}$ & 0.460 \\
\hline $\begin{array}{l}\text { Marital status } \\
\text { Single } \\
\text { Married } \\
\text { Divorced/widow }\end{array}$ & $\begin{array}{c}39(92.9) \\
2(4.8) \\
1(2.4)\end{array}$ & $\begin{array}{c}812(83.9) \\
140(14.5) \\
16(1.7)\end{array}$ & $\begin{array}{c}851(84.3) \\
142(14.1) \\
17(1.7)\end{array}$ & $0.132 * *$ \\
\hline $\begin{array}{l}\text { Education } \\
\text { Elementary school } \\
\text { High school } \\
\text { Bachelor degree } \\
\text { Diploma } \\
\text { Post-graduate }\end{array}$ & $\begin{array}{c}0(0.0) \\
23(54.8) \\
13(31.0) \\
4(9.5) \\
2(4.8)\end{array}$ & $\begin{array}{c}24(2.5) \\
409(42.3) \\
410(42.4) \\
98(10.1) \\
27(2.8)\end{array}$ & $\begin{array}{c}24(2.4) \\
432(42.8) \\
423(41.9) \\
102(10.1) \\
29(2.9)\end{array}$ & $0.352^{* *}$ \\
\hline $\begin{array}{l}\text { Occupation } \\
\text { Student } \\
\text { Employee } \\
\text { Freelancer } \\
\text { Housewife } \\
\text { Retired } \\
\text { Unemployed }\end{array}$ & $\begin{array}{l}34(81.0) \\
3(7.1) \\
0(0.0) \\
0(0.0) \\
0(0.0) \\
5(11.9)\end{array}$ & $\begin{array}{l}655(67.7) \\
154(15.9) \\
18(1.9) \\
37(3.8) \\
10(1.0) \\
94(9.7)\end{array}$ & $\begin{array}{c}689(68.2) \\
157(15.5) \\
18(1.8) \\
37(3.7) \\
10(1.0) \\
99(9.8)\end{array}$ & $0.430^{* *}$ \\
\hline $\begin{array}{l}\text { Monthly family income } \\
\quad<5,000 \\
5,000-9,999 \\
10,000-19,999 \\
20,000-29,999 \\
\geq 30,000\end{array}$ & $\begin{array}{l}\text { yal (SR) } \\
13(31.0) \\
10(23.8) \\
7(16.7) \\
5(11.9) \\
7(16.7)\end{array}$ & $\begin{array}{c}237(24.5) \\
277(28.6) \\
253(26.1) \\
107(11.1) \\
94(9.7)\end{array}$ & $\begin{array}{l}250(24.8) \\
287(28.4) \\
260(25.7) \\
112(11.1) \\
101(10.0)\end{array}$ & $0.330^{* *}$ \\
\hline
\end{tabular}

Test used was chi square test except marked: * t-test; ** Fisher exact. 
the only socio-demographic variable associated with $\mathrm{BDD}$, with younger age in the BDD group compared with a non-BDD group $(20.2 \pm 3.0$ versus $23.0 \pm 7.2, p=0.014)$. The prevalence of BDD was $6.6 \%$ among participants less than 20 years, $3.5 \%$ in those between $20-25$ years, and $1.3 \%$ in above 25 years.

Table 3 shows the use and interest in social media applications among the participants by BDD status. With the exception of Facebook, all other social media applications were heavily used. The use of social media was highest with Snapchat (95.8\%), followed by WhatsApp (93.2\%), YouTube (89.2\%), Instagram (85.9\%), Twitter (79.2\%), and finally, Facebook (4.5\%). The majority $(62.3 \%)$ of participants spent, on average more than 4 hours per day on all social media applications. The time spent in minutes per day was highest with Snapchat $(81.2 \pm 51.2)$, followed by Instagram (57.4 \pm 51.8$), \quad$ YouTube (57.1 \pm 50.5$)$, WhatsApp (49.1 \pm 45.8$)$, Twitter (45.8 \pm 49.3$)$, and finally Facebook (1.5 \pm 10.9$)$. The average number of daily visits of social media applications was highest with Snapchat $(14.3 \pm 18.0)$, followed by Instagram (10.3 \pm 15.0$)$, WhatsApp (10.1 \pm 12.9$)$, Twitter $(8.9 \pm 16.0)$, YouTube (7.9 \pm 13.8$)$, and finally Facebook (0.9 \pm 4.6$)$. The top five topics that received the highest interest of the participants include music, songs, and movies (76.5\%), following celebrities (65.5\%), shopping $(55.5 \%)$, body health and beauty (51.4\%), and nutrition, food, and cooking $(49.4 \%)$. The five topics that received the lowest interest of the participants include business and economy (24.0\%), sex and sex education $(24.8 \%)$, politics $(27.7 \%)$, sports news and competitions (43.2\%), and travel and tourism $(43.8 \%)$. Out of all the variables that characterized the use and interest in social media applications, the following were associated with BDD; spending longer time on Snapchat $(97.9 \pm 51.6$ versus $80.4 \pm 51.1$ minutes per day, $\mathrm{p}=0.036$ ), spending longer time on Instagram (74.6 \pm 59.8 versus $56.7 \pm 51.3$ minutes per day, $p=0.049$ ), and less interest in religious topics $(23.8 \%$ versus $48.1 \%, \mathrm{p}=0.002)$.

Table 4 shows the concerns, harassment, and psychiatric problems among the participants by BDD status. Approximately $60.8 \%$ of all participants (including $100 \%$ of those with BDD) had one or more defects that they were very concerned about. The defects of high concerns were skin disfigurements $(64.2 \%)$, hair issues $(42.3 \%)$, shape or size of the belly $(39.6 \%)$, face disfigurements

Table 3. Use and interest in social media applications by Body Dysmorphic Disorder (BDD) status among included participants $(\mathrm{N}=1010)$.

BDD, $\mathrm{N}=42(\%) \quad$ No BDD, $\mathrm{N}=968(\%) \quad$ Total, $\mathrm{N}=1010(\%) \quad$ p-value

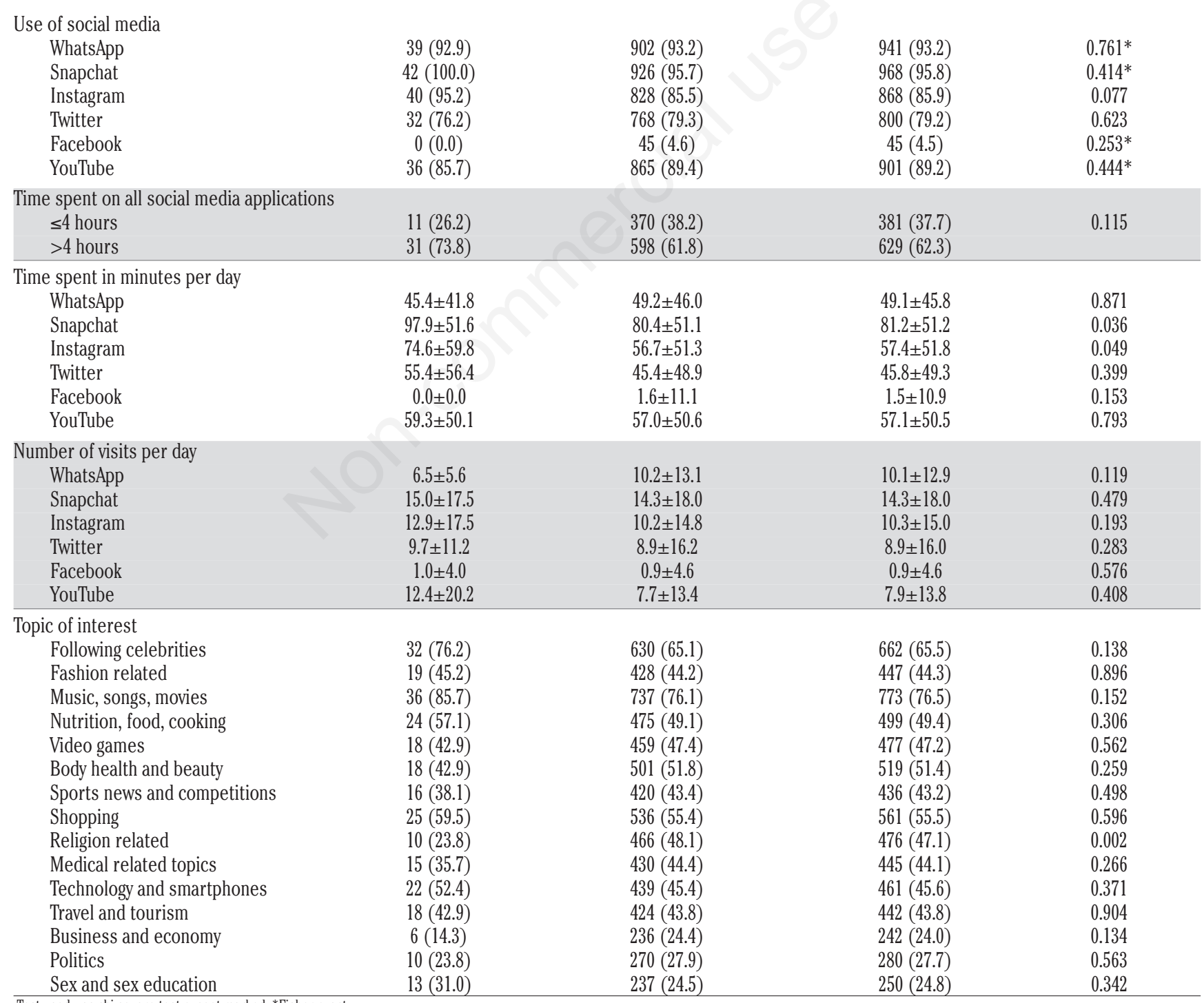


(35.0\%), and shape or size of hips (24.9\%). Participants with BDD had a higher number of defects that they were very concerned about $(\mathrm{p}<0.001)$, especially face disfigurements $(78.6 \%$ versus $63.1 \%, p=0.044)$ but not the shape or size of the belly $(7.1 \%$ versus $42.0 \%, \mathrm{p}<0.001)$. The majority $(70.5 \%)$ of participants reported that their primary concern about appearance was what they think, not what others think. Approximately $23.4 \%$ of the participants were comparing their appearance with famous people in social media, with more comparisons in the BDD group (47.6\% versus $22.3 \%, \mathrm{p}<0.001$ ). Approximately $13.9 \%$ of the participants believed that others see their appearance as severely abnormal, with higher belief in the BDD group $(35.7 \%$ versus $12.9 \%, \mathrm{p}<0.001)$. The majority $(71.2 \%)$ of participants believed that people around them were judging others based on many factors, not just appearance, with less belief in the BDD group $(54.8 \%$ versus $71.9 \%, \mathrm{p}=0.016)$. Approximately $18.9 \%$ of the participants

Table 4. Concerns, harassment, and psychiatric problems by Body Dysmorphic Disorder (BDD) status among included participants $(\mathrm{N}=1010)$.

BDD, $\mathrm{N}=42(\%) \quad$ No BDD, $\mathrm{N}=968(\%) \quad$ Total, $\mathrm{N}=1010(\%) \quad \mathrm{p}$-value

Number of defects you are very concerned about

One or two

$0(0.0)$

$28(66.7)$

Three or more

If very concerned, what are these defects?

Skin (acne, scars, wrinkles, paleness, redness)

Hair

The shape or size of nose, mouth, jaws or lips

The shape or size of belly

The shape or size of hips

The shape or size of breasts

The shape or size of genitals

Skin color

Congenital defects in the hands or anywhere else Others

Type of primary concern about your appearance

What others think

What I think

Comparing your appearance with famous people in social media No

Yes

Beliefs of others on your appearance

Normal

Severely abnormal

Standards by which you judge others

Mainly by appearance

By many factors more important than appearance

Standards by which people around you judge others

Mainly by appearance

By many factors more important than appearance

Did you have appearance-related harassment while using social media?

No

Yes

If yes, what types of harassment?

Mockery

Insult or abuse

Bullying

Threatening or defamation

Incitement to do immoral acts

Others

Were you previously diagnosed with psychiatric problems?

No

Yes

If yes, what psychiatric problems?

Depression $7(50.0)$

Anxiety

Social phobia

Obsessive compulsive disorder

Schizophrenia

Are you consulting a psychiatrist?
$14(33.3)$

33 (78.6)

$15(35.7)$

20 (47.6)

$3(7.1)$

7 (16.7)

$3(7.1)$

$1(2.4)$

$4(9.5)$

$3(7.1)$

$1(2.4)$

15 (35.7)

27 (64.3)

$22(52.4)$

20 (47.6)

27 (64.3)

15 (35.7)

$10(23.8)$

$32(76.2)$

$19(45.2)$

$23(54.8)$

$25(59.5)$

17 (40.5)

$8(47.1)$

$0(0.0)$

$8(47.1)$

$0(0.0)$

$0(0.0)$

$1(5.9)$

28 (66.7)

$14(33.3)$

$7(50.0)$

$4(28.6)$

$1(7.1)$

1 (7.1)

$1(7.1)$
$396(40.9)$

329 (34.0)

243 (25.1)

361 (63.1)

245 (42.8)

195 (34.1)

$240(42.0)$

$146(25.5)$

101 (17.7)

$51(8.9)$

78 (13.6)

$19(3.3)$

$10(1.7)$

$166(29.0)$

$406(71.0)$

752 (77.7)

216 (22.3)

843 (87.1)

$125(12.9)$

$90(9.3)$

878 (90.7)

$272(28.1)$

696 (71.9)

$794(82.0)$

174 (18.0)

97 (55.7)

18 (10.3)

$39(22.4)$

8 (4.6)

$11(6.3)$

$1(0.6)$

$833(86.1)$

135 (13.9)

68 (50.4)

32 (23.7)

$21(15.6)$

$10(7.4)$

$4(3.0)$

Yes

Test used was chi square test except marked: *Fisher exact.
34 (81.0)

8 (19.0)

$899(92.9)$

$69(7.1)$
$396(39.2)$

357 (35.3)

257 (25.4)

$394(64.2)$

$260(42.3)$

$215(35.0)$

$243(39.6)$

$153(24.9)$

$104(16.9)$

$52(8.5)$

$82(13.4)$

$22(3.6)$

$11(1.8)$

$181(29.5)$

$433(70.5)$

774 (76.6)

$236(23.4)$

$870(86.1)$

$140(13.9)$

$<0.001$

$100(9.9)$

$910(90.1)$

291 (28.8)

$719(71.2)$

$819(81.1)$

$191(18.9)$

$105(55.0)$

$18(9.4)$

47 (24.6)

$8(4.2)$

$11(5.8)$

2 (1.0)

861 (85.2)

149 (14.8)

$75(50.3)$

36 (24.2)

22 (14.8)

$11(7.4)$

5 (3.4)

933 (92.4)

77 (7.6)

$<0.001$

0.044

0.368

0.076

$<0.001$

0.200

0.080

$0.244^{*}$

0.450

$0.185^{*}$

$0.544^{*}$

0.358

$<0.001$

$0.006 *$

0.016

$<0.001$

$0.072 *$

$0.732^{*}$

0.001 open access

[page 74] 
reported appearance-related harassment, mainly in the form of mockery $(55.0 \%)$ and bullying (24.6\%). Approximately $14.8 \%$ of the participants were previously diagnosed with psychiatric problems, mainly depression $(50.3 \%)$, anxiety $(24.2 \%)$, and social phobia $(14.8 \%)$. Only $7.6 \%$ of the participants are currently consulting a psychiatrist. BDD group reported more harassment $(40.5 \%$ versus $18.0 \%, p<0.001)$ and more history of psychiatric problems $(33.3 \%$ versus $13.9 \%$, $\mathrm{p}=0.001$ ).

\section{Discussion}

We are reporting the burden, determinants, and impacts of BDD among a community sample of social media users in Saudi Arabia. The current rate of BDD $(4.2 \%)$ is considered higher than the average rates of BDD reported in the general population worldwide, which was estimated at $2.2 \%$ in adolescents, $1.9 \%$ in adults, and $3.3 \%$ in students. ${ }^{5}$ However, the current rates were generally similar to previous studies done in Saudi Arabia. For example, BDD was reported among $4.4 \%$ of female medical students in Riyadh and $12.3 \%$ of female secondary school students in Jeddah. ${ }^{14,15}$ The reported high prevalence of BDD in female secondary school students in Jeddah may be due to the non-exclusion of those with eating disorders who accounted for $8.7 \%$ of the total number of students. ${ }^{14}$

As expected, skin and hair were the areas of highest concern in the current study. The same was generally reported by studies done internationally, ${ }^{21}$ and among students in Saudi Arabia. ${ }^{14,15}$ For example, $75 \%$ and $44 \%$ of female medical students in Riyadh had concerns about the appearance of their skin and hair compared with $64 \%$ and $42 \%$ in the current study. ${ }^{15}$ This may explain the much higher prevalence of BDD among dermatology patients in Saudi Arabia (14.1\%-18.6\%). ${ }^{16,17}$ They usually have more concerns about skin color, acne, and hair loss than the general population. ${ }^{17}$ In our study, those with no BDD are more likely to be bothered by the shape or size of the belly than those with BDD. This is explained by the Body Dysmorphic Disorder Questionnaire (BDDQ) used in this study, which excludes those who have their main concern of appearance as not being thin enough or might become fat from the BDD group.

The prevalence of BDD in the current study was not associated with socio-demographic characteristics, with the exception of age, where BDD was significantly higher among younger participants. The majority of the studies done internationally showed that BDD is more frequent in adolescents and young adults and in females. ${ }^{5}$ In Saudi Arabia, the association between BDD and socio-demographic characteristics was not the focus of the few community studies done, which examined only females with a very narrow age range. ${ }^{14,15}$ Nevertheless, similar to the current findings, BDD in dermatology patients in Saudi Arabia was associated with younger age but not female gender. ${ }^{16}$ Adolescents and young adults are usually more worried and self-conscious about their appearance and are subjected to a higher degree of peer pressure. ${ }^{5}$

Snapchat and Instagram were the most heavily used social media applications in the current study, as evidenced by the duration spent and the number of daily visits. Interestingly, BDD was significantly associated with a longer duration spent on both applications and less interest in religious content. This may indicate a higher interest in sharing and following personal photos and videos among those with BDD. Snapchat specifically is specialized in editing and customizing personal photos and videos, a common behavior in individuals with BDD. ${ }^{2}$ The fact that the study participants were heavily using multiple social media applications may point to the fear of missing out on rewarding experiences that others are having. ${ }^{22}$

It has been suggested that social media can enhance the negative belief in body image by promoting universal features of beauty. ${ }^{11-13}$ Propagating photos, videos, and comments about the ideal face, nose, hair, and skin color can easily trigger the belief that an individual's own body parts are deviated from normal. Consistent with this proposed link, those with BDD in the current study were more likely to compare their own appearance with famous people in social media, emphasize appearance as an important judgment factor, and underscore the abnormalities of their own body. The heavy use of social media, together with its negative impact on body image, may explain the higher rates of BDD in the current study compared with the general population worldwide. ${ }^{5}$

Participants with BDD in the current study reported more harassment and a more frequent history of psychiatric problems than those without BDD. Social media has been associated with harassment, cyberbullying, and other behaviors of antisocial personality disorder. ${ }^{23,24}$ Additionally, it has been suggested that critical events or traumatic incidents such as harassment and repeated criticism about appearance may activate the dysfunctional assumptions seen in individuals with BDD. ${ }^{25}$ Therefore, the more frequent harassment observed in the current study is probably a cause, not an outcome of the disease. Similar to the current findings, those with BDD are at higher risk of psychiatric problems, ${ }^{26}$ and even suicidal attempts. ${ }^{27}$ This may explain the higher prevalence of those with BDD who are seeking psychiatric help in the current and previous studies. ${ }^{7,28}$

The current study is considered the first local study to examine the association between BDD and social media. Additionally, it examined the socio-demographic determinants as well as the impacts of BDD among a relatively large sample size. Nevertheless, the cross-sectional design used does not prove causality and cannot preclude the possibility of response bias. Further, the majority of responses were from young participants (84\% of participants aged $\leq 25$ years), therefore, these results may not be generalized for other age groups. Additionally, the electronic recruitment limits the generalizability of the findings to social media users in Saudi Arabia. This study used the Body Dysmorphic Disorder Questionnaire (BDDQ), and using a different questionnaire or criteria for BDD would have different results accordingly. These limitations, however, are very common in similar studies and probably had a limited impact on the study findings, if any.

\section{Conclusions}

We are reporting a $4.2 \%$ prevalence of BDD among a community sample of social media users in Saudi Arabia, with higher prevalence among those with young age. Skin disfigurements and hair issues were the defects of the highest concern. BDD was significantly associated with a longer duration spent on Snapchat and Instagram. Participants with BDD were more likely to compare their own appearance with famous people in social media and were at higher risk of harassment and psychiatric problems. The findings call for the need to educate the public about the risk of BDD and its consequences and to promote safe social networking, especially among adolescents. Additionally, they may underscore the role of physicians, especially psychiatrists, plastic surgeons, and dermatologists, in identifying BDD among young patients seeking medical care. However, more studies, with larger sample size, are needed to assess the relationship between prolonged social networking, mainly on Snapchat and Instagram, and BDD as well as eating disorders. 


\section{References}

1. Harris D, Carr A. Prevalence of concern about physical appearance in the general population. Br J Plast Surg 2001;54: 223-6.

2. American Psychiatric Association (APA). Diagnostic and statistical manual of mental disorders. (5th Edition). Washington, DC; 2013.

3. Johnson S, Williamson P, Wade TD. A systematic review and meta-analysis of cognitive processing deficits associated with body dysmorphic disorder. Behav Res Ther 2018;107:83-94.

4. Pavan C, Simonato P, Marini M, et al. Psychopathologic aspects of body dysmorphic disorder: a literature review. Aesthetic Plast Surg 2008;32:473-84.

5. Veale D, Gledhill LJ, Christodoulou P, Hodsoll J. Body dysmorphic disorder in different settings: a systematic review and estimated weighted prevalence. Body Image 2016;18:168-86.

6. Ribeiro RVE. Prevalence of body dysmorphic disorder in plastic surgery and dermatology patients: a systematic review with meta-analysis. Aesthetic Plast Surg 2017;41:964-70.

7. Hundscheid T, Van Der Hulst RR, Rutten BP, Leue C. Body dysmorphic disorder in cosmetic surgery - prevalence, psychiatric comorbidity and outcome. Tijdschr Psychiatr 2014;56:51422.

8. IsHak WW, Bolton MA, Bensoussan JC, et al. Quality of life in body dysmorphic disorder. CNS Spectr 2012;17:16775.

9. Phillips KA, Menard W, Fay C, Pagano ME. Psychosocial functioning and quality of life in body dysmorphic disorder. Compr Psychiatry 2005;46:254-60.

10. TNS: Arab Social Media Report. Available from:https://www.extradigital.co.uk/marketing-assets/arabsocialmediareport2015.pdf

11. Holland G, Tiggemann M. A systematic review of the impact of the use of social networking sites on body image and disordered eating outcomes. Body Image 2016;17:100-10.

12. De Vries DA, Vossen HGM, van der Kolk-van der Boom P. Social media and body dissatisfaction: investigating the attenuating role of positive parent-adolescent relationships. J Youth Adolesc 2019;48:527-36.

13. Zeeni N, Doumit R, Abi Kharma J, Sanchez-Ruiz MJ. Media, technology use, and attitudes: associations with physical and mental well-being in youth with implications for evidence-based practice. Worldviews Evid Based Nurs 2018;15:304-12.

14. Alomari AA, Makhdoom YM. Magnitude and determinants of body dysmorphic disorder among female students in Saudi public secondary schools. J Taibah Univ Med Sci 2019; 14:439-47.

15. Shaffi Ahamed S, Enani J, Alfaraidi L, et al. Prevalence of body dysmorphic disorder and its association with body features in female medical students. Iran J Psychiatry Behav Sci 2016;10: e3868.

16. Alonazi H. Prevalence of body dysmorphic disorder in patients attending dermatology clinic in saudi arabia/qassim region. J Med Sci Clin Res 2017;5:30471-9.

17. AlShahwan MA. Prevalence and characteristics of body dysmorphic disorder in Arab dermatology patients. Saudi Med J 2020;41:73-8.

18. Phillips KA. The broken mirror: understanding and treating body dysmorphic disorder. Oxford: Oxford University Press; 2005.

19. Dey JK, Ishii M, Phillis M, et al. Body dysmorphic disorder in a facial plastic and reconstructive surgery clinic: measuring prevalence, assessing comorbidities, and validating a feasible screening instrument. JAMA Facial Plast Surg 2015;17:137-43.

20. Brohede S, Wingren G, Wijma B,
Wijma K. Prevalence of body dysmorphic disorder among Swedish women: a population-based study. Compr Psychiatry 2015;58:108-15.

21. Siegfried E, Ayrolles A, Rahioui H. Body dysmorphic disorder: Future prospects of medical care. Encephale 2018;44:288-90.

22. Franchina V, Vanden Abeele M, van Rooij AJ, et al. Fear of missing out as a predictor of problematic social media use and phubbing behavior among flemish adolescents. Int J Environ Res Public Health 2018;15:2319.

23. Galica VL, Vannucci A, Flannery KM, Ohannessian CM. Social media use and conduct problems in emerging adults. Cyberpsychol Behav Soc Netw 2017;20:448-52.

24. Golder S, Norman G, Loke YK. Systematic review on the prevalence, frequency and comparative value of adverse events data in social media. $\mathrm{Br}$ J Clin Pharmacol 2015;80:878-88.

25. Cororve MB, Gleaves DH. Body dysmorphic disorder: a review of conceptualizations, assessment, and treatment strategies. Clin Psychol Rev 2001;21: 949-70.

26. Van der Meer J, van Rood YR, van der Wee NJ, et al. Prevalence, demographic and clinical characteristics of body dysmorphic disorder among psychiatric outpatients with mood, anxiety or somatoform disorders. Nord J Psychiatr 2012;66:232-8.

27. Snorrason I, Beard C, Christensen K, et al. Body dysmorphic disorder and major depressive episode have comorbidity-independent associations with suicidality in an acute psychiatric setting. J Affect Disord 2019;259:266-70.

28. Dyl J, Kittler J, Phillips KA, Hunt JI. Body dysmorphic disorder and other clinically significant body image concerns in adolescent psychiatric inpatients: prevalence and clinical characteristics. Child Psychiatry Hum Dev 2006;36:369-82. 